\title{
PRERROGATIVAS E INCOMPATIBILIDADES DEL DEFENSOR DEL PUEBLO: ALGUNAS PROPUESTAS DE REFORMA
}

\author{
MAGDALENA GONZÁLEZ ÁLVAREZ \\ Profesora Contratada Doctora de Derecho Constitucional \\ Universidad de Castilla-La Mancha
}

\author{
SUMARIO \\ I. Introducción. \\ II. Prerrogativas. \\ III. Incompatibilidades. \\ IV. Epílogo
}

\section{INTRODUCCIÓN}

La previsión de un adecuado régimen de prerrogativas e incompatibilidades resulta crucial para asegurar la debida independencia y neutralidad en el desempeño del cargo que nos ocupa, y generar con ello la imprescindible confianza y credibilidad de la Institución ante la ciudadanía. La actual regulación presenta algunas dudas interpretativas que intentaremos despejar a continuación en estas notas, y posibilidades de mejora que, a nuestro juicio, sería recomendable introducir, tal y como así se ha previsto, por ejemplo, respecto a determinados comisionados autonómicos.

\section{PRERROGATIVAS}

Previstas en el artículo 6 la Ley Orgánica 3/1981, de 6 de abril, del Defensor del Pueblo (LODP), y en los artículos 1.2 y 2 del Reglamento de Organización y funcionamiento del Defensor del Pueblo, de 6 de abril de 1983 (ROFDF), presentan ciertas especialidades respecto a las prerrogativas parlamentarias, y son aplicables también a sus Adjuntos. Se adquieren desde el momento de la toma de posesión. 


\section{Prohibición de mandato imperativo}

El art. 6.1 LODP prescribe que el Defensor del Pueblo: «no estará sujeto a mandato imperativo alguno. No recibirá instrucciones de ninguna autoridad. Desempeñará sus funciones con autonomía y según su criterio".

No hay mejor manera de garantizar la independencia del Defensor del Pueblo en relación con las Cámaras legislativas que aplicar este instituto ya tradicional en el ámbito legislativo. Con respecto al Defensor del Pueblo y sus Adjuntos, la prohibición del mandato imperativo implica que no están condicionados ni reciben instrucciones, ni del Poder Legislativo, del que son comisionados, ni de ninguno de sus integrantes. Tampoco de ninguna autoridad. Actúan con plena autonomía y libertad de criterio, y ello hasta el punto de encontrase legitimados para recurrir, en su caso, actuaciones tanto del mismo Poder Legislativo, como del Ejecutivo y del Poder Judicial mediante el recurso de inconstitucionalidad y el de amparo.

Ahora bien, tradicionalmente, y en el ámbito parlamentario, la prohibición de mandato imperativo implicaba también que el elegido no debía rendir cuentas ante nadie, ni tenía que justificar ante su distrito electoral el uso de sus poderes. Este alcance de la prohibición del mandato imperativo no resulta hoy totalmente aplicable y menos aún al Defensor del Pueblo. Fundamentalmente porque la Constitución exige a todos los poderes, órganos e instituciones del Estado, junto a la legitimación de origen que otorga la elección y el nombramiento, la legitimación de ejercicio, esto es, la justificación del ejercicio de sus atribuciones y ello para que la discrecionalidad y autonomía en el ejercicio de sus competencias no se convierta en arbitrariedad. Para ello, la Ley Orgánica del Defensor del Pueblo exige a éste dar cuenta anualmente de sus actuaciones al Congreso y al Senado y razonar y justificar adecuadamente las mismas. En este sentido, el Reglamento de Organización y Funcionamiento del Defensor del Pueblo, en su artículo 3, establece que el Defensor sólo es responsable ante las Cortes Generales y los Adjuntos ante el Defensor del Pueblo y la Comisión Mixta Congreso-Senado de relaciones con el Defensor del Pueblo.

\section{INVIOLABILIDAD}

El apartado $2{ }^{\circ}$ del art. $6^{\circ}$ LODF establece que: "El Defensor del Pueblo gozará de inviolabilidad. No podrá ser detenido, expedientado, multado, perseguido o juzgado en razón a las opiniones que formule o a los actos que realice en el ejercicio de las competencias propias de su cargo".

Para la LODF, pues, la inviolabilidad es una prerrogativa por la que el Defensor del Pueblo y los Adjuntos quedan exentos de responsabilidad jurídica por las opiniones y actuaciones realizadas en el ejercicio de sus funciones. Según doctrina del Tribunal Constitucional sobre la inviolabilidad de los parlamentarios, pero perfectamente trasladable a la Institución que nos ocupa, no 
se trata de un privilegio personal, pues lo que se pretende es garantizar la independencia y libertad en la formación de la voluntad de la Institución, preservando un ámbito cualificado de libertad en la crítica y en la decisión sin el cual el ejercicio de las funciones propias del cargo podría resultar mediatizado y frustrado (STC 51/1985, FJ 6. $\left.{ }^{\circ}\right)^{1}$.

En la STC 243/1988, FJ 3, referida a los parlamentarios, la prerrogativa en cuestión se define como un privilegio de naturaleza sustantiva que garantiza la irresponsabilidad jurídica de los parlamentarios por las opiniones manifestadas en el ejercicio de sus funciones, entendiendo por tales aquéllas que realicen en actos parlamentarios y en el seno de cualquiera de las articulaciones de las Cortes Generales o, por excepción, en actos exteriores a la vida de las Cámaras que sean reproducción literal de un acto parlamentario". Pero, en segundo lugar, también cubre los votos emitidos en el ejercicio del cargo, como con irreprochable lógica constitucional expresa el art. 21 del Reglamento del Senado. Lo cual ha sido reconocido por la STC 71/1985, FJ 6, cuando reconoce que ampara las "declaraciones de juicio o de voluntad".

De lo anterior rápidamente se deduce que el ámbito de la inviolabilidad de los parlamentarios y del Defensor del Pueblo no coincide exactamente. En primer lugar, porque no es propio del ejercicio del cargo de Defensor participar en votaciones y, en segundo lugar, porque es mucho más amplio, al proyectarse sobre cualquier actuación realizada en el ejercicio de sus funciones. A esto habría que añadir la observación de que mientras que la actividad de los parlamentarios se desarrolla, en la mayoría de los casos, en el propio recinto parlamentario, la actuación del Defensor supone muy asiduamente el ejercicio de competencias fuera de él. Por tanto, la inviolabilidad del Defensor se proyecta tanto sobre "opiniones" como, en general, sobre todo tipo de "actos" que realice en desarrollo de las "competencias propias de su cargo". Debiendo entender por éstos los que se concretan, partiendo de lo dispuesto en la Constitución, en su propia ley orgánica y en el resto de normativa de desarrollo, y sea cual sea el lugar donde se lleven a cabo ${ }^{2}$.

Por otra parte, tal y como está formulada, se trata de una irresponsabilidad perpetua, es decir, que perdura aun después de terminada la duración de su mandato, y general, pues no se excluye sólo la sanción penal, sino también la civil, administrativa, etc.

1 Para que los miembros de las Cortes Generales puedan actuar como primer foro político del país, abierto a todos los temas de interés público, y cumplir adecuadamente su función de instancia de fiscalización de la actuación del Gobierno, es necesario ahuyentar cualquier factor que provoque inhibición o temor por las opiniones expresadas y por los votos emitidos en el ejercicio de sus funciones.

2 Los actos y opiniones particulares quedarían al margen, ya que la inviolabilidad no constituye un privilegio personal sino una garantía objetiva de una función constitucional prevalente que justifica la quiebra del principio de igualdad. 


\section{INMUNIDAD}

Continúa señalando el apdo. $3 .^{\circ}$ del art. $6^{\circ}$ que nos ocupa que, "en los demás casos, y mientras permanezca en el ejercicio de sus funciones, el Defensor del Pueblo no podrá ser detenido ni retenido sino en caso de flagrante delito, correspondiendo la decisión sobre su inculpación, prisión, procesamiento y juicio exclusivamente a la Sala de lo Penal del Tribunal Supremo ${ }^{3}$. Con ello se está refiriendo a la prerrogativa que tradicionalmente en el ámbito parlamentario se conoce como inmunidad. Siguiendo la doctrina del Tribunal Constitucional y aplicándola al supuesto que nos ocupa, se puede definir la inmunidad como una prerrogativa de naturaleza formal que protege la libertad personal del Defensor frente a detenciones y procesos judiciales que puedan desembocar en una privación de su libertad, fruto de una manipulación política destinada a evitar que la persona designada al efecto pueda continuar con el desempeño de sus funciones, alterándose así la composición y el funcionamiento del órganó .

La inmunidad, tal y como aparece regulada por el art. 6.3 LODF, se diferencia de la inviolabilidad, en primer lugar, por su objeto: en esta última los actos protegidos son los realizados en el ejercicio de las funciones propias del cargo, mientras que la inmunidad protege frente a los restantes, es decir, los que realice en su mera condición de ciudadano, utilizándose literalmente la expresión "en los demás casos" para marcar esta diferenciación 5 . Esto constituye una importante especialidad frente a la inmunidad de Diputados y Senadores, pues respecto a esta última, se estima mayoritariamente que salvo las opiniones y votos expresados en el ejercicio de la función parlamentaria, exentos de cualquier tipo de responsabilidad jurídica en virtud de la prerrogativa de la inviolabilidad, cualquier otro tipo de actuación de los parlamentarios, sea o no en el ejercicio de la funciones propias del cargo, quedaría protegida por la inmunidad ${ }^{6}$. Ello tiene su lógica, pues el ámbito material de

3 La misma referencia se establece en el art. 2.2 ROFDP, salvo que se elimina el término retención.

4 Textualmente, la STC 243/1988, FJ 3 establece lo siguiente: "La inmunidad... es una prerrogativa... que protege la libertad personal de los representantes populares contra detenciones y procesos judiciales que puedan desembocar en privación de libertad, evitando que, por manipulaciones políticas, se impida al parlamentario asistir a las reuniones de las Cámaras y, a consecuencia de ello, se altere indebidamente su composición y funcionamiento". La misma definición se recoge en la STC 206/1992, FJ $3^{\circ}$.

5 No compartimos la opinión de GURRERA ROIG, M. cuando afirma que el Defensor del Pueblo sí podrá ser perseguido y juzgado por los actos que realice en el ejercicio de las competencia propias de su cargo si éstas son constitutivas de delito (con los requisitos y garantías desplegados en este artículo); en su comentario al art. $6 .^{\circ}$ LODP en la obra colectiva Comentarios a la Ley Orgánica del Defensor del Pueblo, cit., pág. 151. A nuestro juicio, como hemos expuesto supra, estas actuaciones estarían exentas de cualquier tipo de responsabilidad jurídica en virtud del amplio reconocimiento de inviolabilidad al respecto.

6 Como señala GARCÍA MORILLO, refiriéndose a la inmunidad parlamentaria: «a diferencia de la inviolabilidad, la inmunidad cubre, además de los actos funcionales del parlamentario, los que no lo son: cualquier procedimiento penal contra un parlamentario debe contar con la concesión 
la inviolabilidad parlamentaria es mucho más exiguo, como hemos visto, que el que rige para la inviolabilidad del Defensor.

Pero también en que rige exclusivamente durante el período de duración de su mandato; en que la protección que otorga se limita exclusivamente al ámbito penal'; y en que, además, dentro de este último tampoco es absoluta, pues el Defensor podría ser detenido o retenido ${ }^{8}$ en caso de flagrante delito?, correspondiendo la decisión sobre su inculpación, prisión y procesamiento exclusivamente a la Sala de lo Penal del Tribunal Supremo. En definitiva, no exime de responsabilidad penal, sino que requiere el cumplimiento de determinados requisitos para su exigencia, relacionándose directamente la inmunidad con el aforamiento especial ${ }^{10}$.

\section{Aforamiento ESPECIAL}

El aforamiento especial opera como complemento y cierre de la inviolabilidad e inmunidad con el objeto de asegurar que el órgano encargado de un posible enjuiciamiento penal del Defensor goce de las más altas cotas de independencia y cualificación jurídica, de la misma forma que ocurre con otras altas autoridades del Estado. Se trata de la Sala de lo Penal del Tribunal Supremo.

Por lo demás este fuero particular produce dos consecuencias negativas. Por un lado, la imposibilidad de someter el fallo de la Sala segunda a una re-

del suplicatorio para ser proseguido", en Derecho Constitucional, Vol. II, 4. a edición, Tirant lo Blach, Valencia, 2000, pág. 80. También en este sentido se pronuncia PEÑARANDA RAMOS, J.L., en su comentario al art. $71 \mathrm{CE}$, en la obra colectiva dirigida por O. ALZAGA VILLAAMIL: Comentarios a la Constitución española de 1978, Edersa, Madrid, 2006, pág. 369.

7 En este sentido, la sentencia del Tribunal Constitucional 9/1990, de 18 de enero, en relación al ámbito parlamentario, estimó la inconstitucionalidad de la regulación de la Ley Orgánica 3/1985, de 29 de mayo, que reformó el art. 2.2 de la Ley Orgánica 1/1982, de 5 de mayo, de protección civil del derecho al honor, a la intimidad personal y familiar y a la propia imagen, en el sentido de exigir autorización parlamentaria para poder someter a un Diputado o Senador al procedimiento establecido en la misma, teniendo en cuenta que la responsabilidad que podría derivarse de la infracción de dicha ley era puramente civil.

8 Redacción tributaria en este punto de la dicción del Reglamento provisional de 1977.

9 La idea de flagrancia, con todas sus dificultades, ha sido abordada por la jurisprudencia constitucional en la STC 341/ 1993, que admite que es posible ureconocer la arraigada imagen de la flagrancia como situación fáctica en la que el delincuente es "sorprendido" o visto directamente o percibido de otro modo en el momento de delinquir o en circunstancias inmediatas a la perpetración del ilícito".

10 En relación con la inculpación o el procesamiento contra diputados y senadores lo que impide la Constitución es que puedan llevarse a cabo "sin la previa autorización de la Cámara respectiva", lo que conduce a la cuestión del denominado suplicatorio. Lo que en términos generales se denomina como suplicatorio no es técnicamente sino el instrumento procesal en el que la autoridad judicial solicita a la Cámara la autorización para proceder (art. 5 de la Ley de 9 de febrero de 1912 y art. 755 LECrim). Este instrumento procesal es de la máxima importancia, por cuanto que es el documento que desencadena el procedimiento para su tramitación previsto en los Reglamentos de ambas Cámaras. Es precisamente sobre esta petición sobre la que se pronuncian los Plenos. 
visión judicial, dado que por su propia condición no existe recurso ordinario frente a sentencia del Tribunal Supremo. Esto podría perjudicar el derecho del condenado a obtener una revisión por una instancia superior, reconocido por el propio Tribunal Constitucional como parte del derecho a un proceso con todas las garantías ${ }^{11}$, derecho también reconocido en el art. 14.5 del Pacto Internacional de Derechos Civiles y Políticos de 1966. Siendo consciente de esta contradicción, el Tribunal Constitucional la salva, tal y como señala entre otras la STC 64/2001, FJ 7, en la forma siguiente: “... ha de entenderse que el constituyente efectuó una inicial ponderación del derecho al doble grado de jurisdicción de Diputados y Senadores y de las necesidades de protección tanto de la independencia de la propia institución parlamentaria como del Poder Judicial. Ponderación que... no resulta ajena al entendimiento de los países de nuestro entorno jurídico-constitucional respecto del alcance de este derecho, pues como excepción al mismo se admite el caso en el que el Tribunal Superior en el orden penal haya conocido en primera y única instancia (art. 2.2 del Protocolo 7 CEDH). Dicha ponderación convierte en innecesaria una ulterior valoración expresa de la proporcionalidad de la restricción de este derecho fundamental, en otro caso imprescindible, dado que, como este Tribunal tiene declarado, toda restricción de derechos fundamentales debe responder a un fin constitucionalmente legítimo y ser instrumento necesario y adecuado para alcanzar dicho objetivo".

Por otro lado, este fuero puede extenderse a otras personas imputadas en la misma causa, ya que la LECrim (arts. 17.1, 272.3, 300) establece el enjuiciamiento conjunto en un único procedimiento de los delitos conexos. Con ello, estos últimos se ven privados de su derecho a recurrir una posible sentencia condenatoria ante una instancia superior. La STC 64/2001, dio por buena esta consecuencia seguramente por lo inevitable del mandato del art. $71.3 \mathrm{CE}$.

\section{INCOMPATIBILIDADES}

La misión constitucional del Defensor del Pueblo precisa la previsión de un régimen de incompatibilidades que garantice, por un lado, su independencia y objetividad; y por otro, que propicie un funcionamiento eficaz del mismo. Objetivos estos que podrían resultar menoscabados de permitirse ampliamente el desempeño simultáneo de otras actividades públicas o privadas. A este propósito responde la regulación establecida en el art. 7 LODP, que en virtud del apartado $4 .^{\circ}$ del artículo $8^{\circ}$ de esta misma Ley será también de aplicación a los Adjuntos. Regulación que plantea una serie de significativos interrogantes que intentaremos resolver en los sucesivos epígrafes de este trabajo.

11 SSTC 42/1982, FJ 3; 76/1982, FJ 5, 60/1985, FJ 2, 140/1985, FJ 2; 30/1986, FJ 2, 190/1994 FJ 2; y 133/2000, FJ 3, entre otras. 


\section{Causas de incompatibilidad}

Dispone el apartado $1^{\circ}$ del art. 7 de la LODP que «la condición de Defensor del Pueblo es incompatible con todo mandato representativo; con todo cargo político o actividad de propaganda política ${ }^{12}$; con la permanencia en el servicio activo de cualquier Administración pública; con la afiliación a un partido político o el desempeño de funciones directivas en un partido político o en un sindicato, asociación o fundación, y con el empleo al servicio de los mismos; con el ejercicio de las carreras judicial y fiscal, y con cualquier actividad profesional, liberal, mercantil o laboral".

Este régimen de incompatibilidades, que pretende garantizar la dedicación casi exclusiva al cargo, guarda cierta semejanza con el establecido para los miembros del Tribunal Constitucional en el artículo 159.4 de la Constitución española, algo más desarrollado en el artículo 19 de la LOTC ${ }^{13}$. Su diferencia más notoria es que no rige el amplio régimen de incompatibilidades establecido en la LOPJ para los miembros del Poder Judicial. Algún autor ha señalado, precisamente, que las incompatibilidades del Defensor del Pueblo debían ser las mismas que las establecidas para el Poder Judicial y el Ministerio Fiscal, así como aquellas otras necesarias para asegurar la independencia en sus actuaciones. Sin embargo, en la correspondiente tramitación parlamentaria fue rechazada en el Congreso la enmienda número 85 al texto de la proposición de ley, presentada en este sentido por el Grupo de Coalición Democrática.

Detengámonos más detenidamente a continuación en algunas de estas causas:

\section{- Con todo mandato representativo}

De ello hay que deducir que la condición de Defensor del Pueblo es incompatible con todos los cargos de elección popular de cualquier ámbito territorial, a saber: diputado o senador de las Cortes Generales, parlamentarios europeos, diputados autonómicos, concejales, diputados provinciales, miembros de Cabildos y Consejos Insulares, miembros de las Juntas Generales de

12 En el artículo 70.1 c) de la Constitución se declara la incompatibilidad del Defensor del Pueblo con el cargo de Diputado o Senador, y en el mismo precepto se señala la inelegibilidad del Defensor del Pueblo como Diputado o Senador.

13 Según el apdo. $1^{\circ}$ de este último artículo: «El cargo de Magistrado del Tribunal Constitucional es incompatible: $1^{\circ}$ con el de Defensor del Pueblo; $2^{\circ}$ con el de Diputado y Senador; $3^{\circ}$ con cualquier cargo político o administrativo del Estado, las Comunidades Autónomas, las provincias u otras Entidades locales; $4^{\circ}$ con el ejercicio de cualquier jurisdicción o actividad propia de la carrera judicial o fiscal; $5^{\circ} \mathrm{con}$ empleos de todas clases en los Tribunales y Juzgados de cualquier orden jurisdiccional; $6^{\circ}$ con el desempeño de funciones directivas en los partidos políticos, sindicatos, asociaciones, fundaciones y colegios profesionales y con toda clase de empleo al servicio de los mismos; $7^{\circ}$ con el desempeño de actividades profesionales o mercantiles. En lo demás, los miembros del Tribunal Constitucional tendrán las incompatibilidades propias de los miembros del Poder Judicialw. 
los Territorios Históricos, de las Juntas Comarcales de elección indirecta de varias Comunidades, de las Asambleas de las dos Ciudades Autónomas, alcaldes de los municipios con régimen de concejo abierto, etc.

Por otra parte, también los senadores designados por las Comunidades Autónomas entrarían en nuestra opinión dentro de esta categoría. Es cierto que dado que su designación proviene de la correspondiente Asamblea Legislativa de la Comunidad Autónoma, la determinación de la relación representativa que subyace a este mandato podría plantear ciertos interrogantes. De hecho, en algunas credenciales de los mismos se afirma que lo son en representación de una Comunidad Autónoma. Sin que ello deje de ser cierto, no lo es menos que los designados lo son por ser miembros de un determinado grupo político o, al menos, por ser propuestos por uno de ellos. De hecho, una vez que los senadores designados se incorporan al Senado no existen, en puridad, diferencias sustanciales con los senadores electos y aquéllos pasan a formar parte de los Grupos Parlamentarios constituidos en torno a las fuerzas políticas de diverso signo. No se conoce aún ningún caso en el que el conjunto de los senadores designados por una Comunidad Autónoma hayan pasado a formar parte de un grupo parlamentario específico diferente de los ya constituidos. De forma que resumiendo, y como conclusión general, se puede afirmar que independientemente del origen de su mandato y de la especificidad de las causas de su cese, no hay diferencias ni en las funciones ni en el estatuto que este tipo de senadores designados tiene respecto de los senadores electos ${ }^{14}$.

Por razones similares, lo mismo habría que entender respecto de los Diputados Provinciales, elegidos por y entre los concejales de los Ayuntamientos de la provincia respectiva.

\section{- Con todo cargo politico o actividad de propaganda política}

En esta causa de incompatibilidad se comprende una larga lista de figuras cuyo estatuto es político como consecuencia de integrar los poderes ejecutivos estatal, autonómico o de la Unión Europea, o de la designación por parte de órganos de gobierno e instituciones territoriales: Presidente del Gobierno, Vicepresidentes del Gobierno, ministros, comisarios y ministros europeos, Presidentes de Comunidades Autónomas, consejeros, Presidentes de Diputaciones Provinciales, alcaldes, altos cargos de cualquier Administración ${ }^{15}$, etc. Pero es mucho más amplia, al comprender también cualquier actividad de

14 ALBA NAVARRO, M., en su sinopsis sobre el art. 69 de la Constitución española, que se ofrece en el Portal de la Constitución de la página web del Congreso de los Diputados.

15 Sin ánimo de ser exhaustivos, nos estamos refiriendo a cargos como los siguientes: Secretarios de Estado, Secretarios Generales, Directores Generales, Subsecretarios, Secretarios Generales Técnicos y Directores de Gabinetes, todos ellos en relación al Estado central, y órganos similares de las Comunidades Autónomas, de la Unión Europea y de las Corporaciones Locales; Delegados del Gobierno en las Comunidades Autónomas y en Ceuta y Melilla, etc. 
propaganda política. De todas formas, respecto de todos aquellos que simultanean esta condición con mandato parlamentario o representativo en general, es posible también su catalogación en la anterior causa de incompatibilidad.

\section{- Con la afiliación a un partido político o el desempeño de funciones di- rectivas o empleo al servicio del mismo}

Resulta difícilmente discutible que una cosa es que toda persona tenga sus propias ideas políticas y otra, bien distinta, que mantenga compromisos ideológicos formalizados con un partido político. Ciertamente, el legislador no ha pretendido hacer del Defensor "un modélico sujeto apolítico y neutro en el sentido más radical de estos términos, carente, en consecuencia, de la más mínima convicción y arraigo con su entorno" ${ }^{16}$. Y aunque lo realmente relevante en la práctica sea la imparcialidad en el ejercicio de su función, no parece lo más adecuado para la imagen de la Institución que durante el desempeño de la misma su titular mantenga lazos de militancia política ${ }^{17}$, o más aún, ejerza funciones directivas o desempeñe cualquier empleo al servicio del mismo ${ }^{18}$.

Por similares razones, a nuestro juicio, debería haberse previsto también como causa de incompatibilidad la simple afiliación a un sindicato. De hecho, así se contempla para muchos Defensores del Pueblo autonómicos. Al fin y al cabo cabe también conceptuar en la actualidad a los sindicatos como

16 ANGUITA SUSI, A.: El Defensor del Pueblo andaluz y la tutela de los derechos fundamentales. Medios mecanismos y procedimiento, Coedición Defensor del Pueblo Andaluz y Tirant lo Blanch, Valencia, 2006, pág. 61.

17 En cualquier caso, esta opción legislativa ha sido objeto de fuertes críticas por parte de cierto sector de la doctrina española que considera que prohibir la militancia en un partido político es una medida desproporcionada que "pone una vez más de relieve el lastre cultural de residuales connotaciones franquistas (equívoca intelección del "apoliticismo y el "antipartidismo"), CARBALLO ARMAS, P.: El Defensor del Pueblo. El Ombudsman en España y en el Derecho comparado, Tecnos, Madrid, 2003, pág. 169. Igualmente crítico con dicha opción legislativa se muestra RUIZ RICO, J.J.: "El Defensor del Pueblo andaluz", El Estatuto de Andalucía, Vol. IV, Ariel, Barcelona, 1990, pág. 147. Por su parte, MARTínEZ ALARCÓN, M. ${ }^{a}$ L., se pregunta si la sociedad española es lo suficiente madura desde una perspectiva democrática para comprender que la adscripción política, siempre y cuando ésta no se utilice para resolver los conflictos del ciudadano con la Administración, no tiene por qué suponer una merma para el funcionamiento eficaz de este instituto, en El Defensor del Pueblo de Castilla-La Mancha en la teoría y en la práctica, Ediciones Parlamentarias de Castilla-La Mancha, Toledo, 2005, pág. 22.

18 Algunos autores van más allá y estiman que sería muy recomendable que quien aspire al cargo no haya tenido en los últimos tiempos una activa militancia política —sería injusto exigir que el candidato no haya pertenecido jamás a un partido político, pues la experiencia y el compromiso con la sociedad que representa esa militancia no es en sí mismo desdeñable-, considerando un auténtico fraude político a la finalidad perseguida por la ley, darse de baja en un partido inmediatamente antes de ser nombrado. Es el caso de Foro Iruña: ARMENDÁRIZ, M., AYERDI, V., CABASÉS, I., CAMPO, J.L., y otros: "En torno al Defensor del Pueblo de Navarra” en http://webs.ono.com/mizubel/defensor.htm (19/09/2000). Reflexiones efectuadas en torno al Defensor del Pueblo navarro pero perfectamente trasladables a la institución nacional. Este foro de opinión se forma en junio del año 2000 e integra a personas procedentes de diversas formaciones políticas y sociales de Navarra. 
"Sujetos políticos" que, con los medios que le son propios —negociación colectiva, huelga, autotutela de intereses en variadas formas, manifestaciones, información, participación institucional, etc.- negocian con el poder político su propio proyecto de sociedad, extendiéndose su campo de acción a la concertación social de las políticas económicas y sociales, a la negociación política con el poder público de las líneas de actuación y de reforma de la sociedad y del Estado.

- Con el ejercicio de funciones directivas o con el empleo al servicio de sindicatos, asociaciones y fundaciones

Sin embargo, como se ha puesto de manifiesto, las asociaciones o fundaciones pueden tener ámbitos de actuación muy ajenos al mundo de la política, por lo que, en principio, esta causa de incompatibilidad podría resultar desproporcionada. Con su previsión, una vez más, se intenta preservar ampliamente la neutralidad e independencia de la Institución. Además de evitar la interferencia de otros cometidos profesionales, se trata de alejar la posibilidad de recibir influencias o sufrir condicionamientos por parte de colectivos y grupos de presión. Tanto más cuanto estas personas jurídicas podrían instar ante el Defensor la correspondiente queja que posteriormente éste habrá de conocer ${ }^{19}$.

\section{- Con cualquier actividad profesional, liberal, mercantil o laboral}

El inciso final de este art. 7.1 LODP supone una especie de claúsula de cierre que prácticamente no le permite actividad alguna sea del tipo que sea. Su generalidad parece indicar que ni tan siquiera la docencia o la investigación sería compatible con el ejercicio del cargo. Detengámonos un poco más en esto último.

El artículo 389.5 de la LOPJ considera las actividades docentes compatibles con el cargo de Juez o Magistrado, pero nada se dice en el artículo 7 de la LODP. Por su parte, en los artículos 3.1 y 4.1 de la Ley 53/1984, de 26 de diciembre, de Incompatibilidades del Personal al Servicio de la Administración Pública, se contempla para tal personal la posibilidad de desempeñar un segundo puesto de trabajo en la actividad docente, previa autorización de compatibilidad, como profesor universitario asociado en régimen de dedicación no superior a la de tiempo parcial. Asimismo, hay que tener en cuenta lo dispuesto en el artículo 157.4 de la Ley Orgánica de Régimen Electoral General, que matizando el régimen de dedicación absoluta de Diputados y Senadores dispone que: "no obstante lo dispuesto en el apartado anterior, los parlamentarios que reúnan la condición de Profesores Universitarios podrán

19 Espín Templado, E.: Comentarios a la Ley Orgánica del Tribunal Constitucional, Coord. J.L. REQUEJO PAGÉS, Coedición del Tribunal Constitucional y Boletín Oficial del Estado, Madrid, págs. 326-327, aunque en relación a la misma causa de incompatibilidad establecida en el art. 19 de la Ley Orgánica del Tribunal Constitucional para los magistrados del Tribunal Constitucional. 
colaborar, en el seno de la propia Universidad, en actividades de docencia o investigación de carácter extraordinario, que no afecten a la dirección y control de los servicios, pudiendo sólo percibir por tales actividades las indemnizaciones reglamentarias establecidas".

A nuestro juicio la duda ha de resolverse en sentido negativo: el Defensor ha de desempeñar su función en régimen de dedicación exclusiva. Conclusión que ha de derivarse no sólo del contenido y olvido de la función docente en el artículo 7 de la Ley Orgánica del Defensor del Pueblo, sino además, del artículo 31.1 del Reglamento de Organización y Funcionamiento del Defensor del Pueblo, que establece textualmente que para el personal al servicio del Defensor del Pueblo "el régimen de prestación de servicios será el dedicación exclusiva para todo el personal,, por lo que es perfectamente razonable entender que si tal ha de ser el régimen de dedicación del personal subordinado al Defensor, con mayor motivo ha de serlo para éste ${ }^{20}$. Es cierto que mediante Resolución de 26 de septiembre de 2000 y de 3 de octubre de 2000, de las Mesas del Congreso de los Diputados y del Senado, se modificó el apartado $2^{\circ}$ de este art. 31, estableciéndose la posibilidad de que los Asesores del Defensor del Pueblo sean contratados para desarrollar funciones docentes o de investigación en Universidades o en otras instituciones académicas que posean naturaleza y fines análogos, si bien se advierte de que, en todo caso, tales actividades se desempeñarán en régimen de dedicación a tiempo parcial y sin que puedan menoscabar la prestación del servicio en el Defensor del Pueblo, debiendo obtener el reconocimiento de la compatibilidad que resolverá el Defensor del Pueblo oída la Junta de Coordinación y Régimen Interior, previo informe del Secretario General. Pero no existe disposición similar que permita tal compatibilidad en relación al Defensor y sus Adjuntos ${ }^{21}$.

Otra cuestión relacionada con lo ya expuesto es si son compatibles las colaboraciones esporádicas del Defensor del Pueblo y sus Adjuntos en Universidades u otros foros científicos, académicos o de relevancia social. Nos mostramos partidarios de interpretar restrictivamente esta posibilidad, de forma que hay que estimar incompatible con el cargo de Defensor cualquier forma de colaboración académica o de investigación que entrañe el ejercicio de una actividad continuada y remunerada. Dentro de las colaboraciones esporádicas, por razones lógicas, hay que estimar perfectamente admisibles, aunque no exclusivamente, las colaboraciones dimanentes de las relaciones institucionales que el Defensor ha de desarrollar en los distintos ámbitos sociales, que en ningún caso habrán de ser remuneradas, ya que en este supuesto nos encontraríamos ante el ejercicio del cargo propiamente dicho ${ }^{22}$.

20 En este sentido se pronuncia también BRUÑÉN BARBERÁ, F.H., en su comentario al art. $7^{\circ}$ LODP, en la obra colectiva: Comentarios a la Ley Orgánica del Defensor del Pueblo, dirigida por A. ROVIRA VIÑA, Aranzadi, Navarra 2002, pág. 168.

21 Adjuntos a quienes "ex" artículo 8 de la LODP, se aplica el régimen de incompatibilidades establecido en el artículo 7.

22 BRUÑÉN BARBERÁ, F.M., se muestra partidario también de que el Defensor del Pueblo no pueda recibir remuneración por las colaboraciones esporádicas ajenas a aquéllas que dimanan de 
En el caso de producción y creación literaria, artística, científica y técnica, así como de las publicaciones derivadas de éstas, siempre que no se originen como consecuencia de una relación de empleo o de prestación de servicios, estimamos que no debiera existir incompatibilidad, pues así se establece también en el artículo 19.f) de la citada Ley 53/1984, de 26 de diciembre, de Incompatibilidades del Personal al Servicio de la Administración Pública, cuya filosofía cabría perfectamente trasladar al ámbito de la Institución que nos ocupa. Si bien el buen juicio del Defensor deberá llevarle a un ejercicio sumamente mesurado de sus creaciones intelectuales, de forma que no resulte perjudicial en lo más mínimo a su dedicación a las funciones propias del cargo.

\section{LA ADMINISTRACIÓN DEL PATRIMONIO PERSONAL O FAMILIAR}

Obviamente, el Defensor debe poder realizar las actividades oportunas para la mera administración de su patrimonio personal o familiar, pero este punto hubiese precisado de su correspondiente regulación, especificándose, por ejemplo, qué actividades no deben ser consideradas de mera administración patrimonial al poder suponer un detrimento de las funciones propias del cargo o comprometer su imparcialidad e independencia ${ }^{23}$.

En este sentido, por ejemplo, el art. 159.3.a) de la LOREG, inspirado en parte en las previsiones del art. 12 de la Ley 53/1984, de 26 de diciembre, de incompatibilidades del personal al servicio de las Administraciones públicas, establece que "en ningún caso tendrán esta consideración las actividades privadas cuando el interesado, su cónyuge o persona vinculada a aquél en análoga relación de convivencia afectiva y descendientes menores de edad, conjunta o separadamente, tengan participación superior al 10 por 100 en actividades empresariales o profesionales de toda índole que tengan conciertos, concesiones o contratos con Organismos o Empresas del sector público estatal, autonómico o local". Por su parte, el art. 6 de la Ley 5/2006, de 10 de abril, de regulación de los conflictos de intereses de los miembros del Gobierno y de los altos cargos de la Administración General del Estado, establece determinadas limitaciones patrimoniales en participaciones societarias:

«1. (...) no podrán tener, por sí o junto con su cónyuge, sea cual sea el régimen económico matrimonial, o persona que conviva en análoga relación de afectividad e hijos dependientes y personas tuteladas, participaciones directas o indirectas superiores a un diez por ciento en empresas en tanto tengan conciertos o contratos de cualquier naturaleza, con el sector público es-

sus propias relaciones institucionales. Y ello para preservar su imagen pública frente a cualquier crítica social por el percibo de dichas cantidades; en su comentario al artículo $7^{\circ}$ de la LODF en la obra colectiva: Comentarios a la Ley Orgánica del Defensor, cit., págs. 168-169.

23 BRUÑÉN BARBERÁ, F.M., ibídem, pág. 169. 
tatal, autonómico o local, o sean subcontratistas de dichas empresas o que reciban subvenciones provenientes de la Administración General del Estado. 2. En el supuesto de las sociedades anónimas cuyo capital social suscrito supere los 600.000 euros, dicha prohibición afectará a las participaciones patrimoniales que sin llegar a este porcentaje supongan una posición en el capital social de la empresa que pueda condicionar de forma relevante su actuación. 3.En el supuesto de que la persona que sea nombrada para ocupar un puesto de los comprendidos en el artículo 3, poseyera una participación en los términos a los que se refieren los apartados anteriores, tendrá que desprenderse de ella en el plazo de tres meses, contados desde el día siguiente a su nombramiento. Si la participación se adquiriera por sucesión hereditaria u otro título gratuito durante el ejercicio del cargo, tendrá que desprenderse de ella en el plazo de tres meses desde su adquisición. Dicha participación y posterior transmisión serán, asimismo, declaradas a los Registros de Actividades y de Bienes y Derechos Patrimoniales en la forma que reglamentariamente se determine".

De todos modos, la mera administración patrimonial no puede entrañar el ejercicio de actividades profesionales, liberales o mercantiles, por lo que tampoco podrá el Defensor ejercer cargos directivos en sociedades o empresas mercantiles, públicas o privadas.

\section{Declaración de actividades y Bienes patrimoniales}

Las declaraciones de intereses constituyen quizás el medio de mayor significación y eficacia para evitar el tráfico de influencias. Según la experiencia de los países con mayor tradición en la adopción de este tipo de medidas, técnicas preventivas como ésta demuestran mayor eficacia que los instrumentos represivos de carácter sancionador ante la comisión de infracciones penales o administrativas en materia de conflictos de intereses. Por lo demás, ambas técnicas, lejos de ser contradictorias, resultan concurrentes y aun complementarias.

En el art. 11 de la Ley 5/2006, de 10 de abril, de conflictos de intereses de los miembros del Gobierno y Altos Cargos de la Administración, se prevé la obligación de los miembros del Gobierno y altos cargos de la Administración de efectuar declaración de las actividades que desempeñen y de las que vayan a realizar una vez que hubiesen cesado en el ejercicio de los cargos, declaración que se realiza ante el Registro de Actividades de Altos Cargos a que se refiere el artículo 14.2 de la Ley. Tal declaración debe tener lugar en el plazo de los tres meses siguientes a la fecha de toma de posesión y cese, respectivamente, en el alto cargo, así como cada vez que el interesado inicie una nueva actividad de las que son objeto de regulación en esta Ley. El órgano competente para la gestión del régimen de incompatibilidades es la Oficina de Conflictos de Intereses adscrita orgánicamente al Ministerio de Administraciones Públicas y que en el ejercicio de las competencias previstas en esta Ley 
actuará con plena autonomía funcional. Este órgano será el encargado de requerir a quienes sean nombrados o cesen en un alto cargo el cumplimiento de las obligaciones previstas en esta Ley.

En cuanto a la declaración de bienes y derechos, el artículo 12 de esta misma Ley establece lo siguiente: «1. Quienes tengan la condición de alto cargo están obligados a formular en el Registro de Bienes y Derechos Patrimoniales de altos cargos, en los términos que reglamentariamente se establezcan, una declaración patrimonial, comprensiva de la totalidad de sus bienes, derechos y obligaciones. Voluntariamente, su cónyuge o persona con quien conviva en análoga relación de afectividad podrá formular esta declaración, que será aportada por el alto cargo. La declaración patrimonial comprenderá, al menos, los siguientes extremos: a) Los bienes, derechos y obligaciones patrimoniales que posean. b) Los valores o activos financieros negociables. c) Las participaciones societarias. d) El objeto social de las sociedades de cualquier clase en las que tengan intereses el alto cargo, su cónyuge, sea cual sea el régimen económico matrimonial o persona que conviva en análoga relación de afectividad e hijos dependientes y personas tuteladas. e) Las sociedades participadas por aquellas otras que sean objeto de declaración según el apartado c) con señalamiento de sus respectivos objetos sociales. 2. La declaración a que se refiere el apartado 1 de este artículo se efectuará en el improrrogable plazo de tres meses siguientes a las fechas de toma de posesión y cese, respectivamente, en el alto cargo. 3. Los altos cargos aportarán junto con las declaraciones iniciales y las del cese, así como anualmente, una copia de la última declaración tributaria correspondiente al Impuesto sobre la Renta de las Personas Físicas y al Impuesto sobre el Patrimonio que haya tenido obligación de presentar el declarante ante la Administración tributaria. También se podrá aportar la declaración voluntaria de su cónyuge o persona con quien conviva en análoga relación de afectividad referida a estos tributos. Dichas declaraciones se depositarán en el Registro como información complementaria, rigiéndose el acceso a las mismas por su normativa específica. 4. La declaración anual correspondiente al Impuesto sobre la Renta de las Personas Físicas y, en su caso, al Impuesto sobre el Patrimonio, a que hace referencia el apartado anterior, se presentará en el improrrogable plazo de tres meses desde la conclusión de los plazos legalmente establecidos para su presentación. 5. El Registro de Bienes y Derechos Patrimoniales recibirá las declaraciones y las copias y de apreciarse defectos formales, se requerirá su subsanación al interesado".

El Registro de Actividades de Altos Cargos tiene carácter público (art. 14.2), y el Registro de Bienes y Derechos Patrimoniales, en cambio, carácter reservado (art. 14.3).

En cuanto a los Diputados y Senadores, el artículo 160 de la Ley Orgánica de Régimen Electoral General dispone que: «1. Los Diputados y Senadores, con arreglo a las determinaciones de los respectivos Reglamentos de las Cámaras, están obligados a formular declaración de todas las actividades que puedan constituir causa de incompatibilidad conforme a lo establecido en esta 
Ley Orgánica y de cualesquiera otras actividades que les proporcionen o puedan proporcionar ingresos económicos, así como de sus bienes patrimoniales, tanto al adquirir como al perder su condición de parlamentarios, así como cuando modifiquen sus circunstancias. 2. Las declaraciones sobre actividades y bienes se formularán por separado conforme a los modelos que aprobarán las Mesas de ambas Cámaras en reunión conjunta y se inscribirán en un Registro de Intereses, constituido en cada una de las propias Cámaras bajo la dependencia directa de sus respectivos Presidentes, a los efectos del presente artículo y a los que determinen los Reglamentos de las mismas Cámaras. La declaración de actividades incluirá: a) Cualesquiera actividades que se ejercieren y que puedan constituir causa de incompatibilidad, conforme al número 2 del artículo 159. b) Las que, con arreglo a la Ley, puedan ser de ejercicio compatible. c) En general, cualesquiera actividades que proporcionen o puedan proporcionar ingresos económicos. El contenido del Registro de Intereses tendrá carácter público, a excepción de lo que se refiere a bienes patrimoniales. La instrucción y la resolución de todos los procedimientos relativos al Registro de Intereses y a las actividades de los Diputados y Senadores, salvo lo previsto en los restantes apartados de este artículo y en el artículo 159.3 c) corresponderá al Presidente de cada Cámara. 3. El Pleno de la Cámara resolverá sobre la posible incompatibilidad, a propuesta de la Comisión correspondiente, que deberá ser motivada y, en el supuesto de actividades privadas, basarse en los casos previstos en el número 2 del artículo 159 , y, si declara la incompatibilidad, el parlamentario deberá optar entre el escaño y el cargo, actividad, percepción o participación incompatible. En el caso de no ejercitarse la opción, se entiende que renuncia al escaño. 4. Declarada por el Pleno correspondiente la reiteración o continuidad en las actividades a que se refiere el apartado a) o en la prestación de servicios a que alude el apartado d), ambos del número 2 del artículo anterior, la realización ulterior de las actividades o servicios indicados llevará consigo la renuncia al escaño, a lo que se dará efectividad en la forma que determinen los Reglamentos de las Cámaras".

Pues bien, expuesto el régimen de declaración de actividades y bienes de los miembros del Gobierno, altos cargos de la Administración y Diputados y Senadores, resulta sorprendente que no exista ninguna previsión normativa similar en relación con el Defensor, precisándose una reforma en este sentido. Como señala Bruñén Barberá, la figura del Defensor no debe estar rodeada de menos garantías legales en orden a garantizar su objetividad e independencia que la de parlamentarios y altos cargos ${ }^{24}$. Así, por ejemplo, en la Ley 7/2001, de 31 de julio, del Diputado del Común de Canarias, se ha introducido el deber de presentar declaración de bienes y actividades en su artículo 5.3: "Antes de la toma de posesión, el Diputado del Común formulará por escrito ante la Mesa de la Cámara declaración de sus bienes patrimoniales y actividades susceptibles de proporcionar ingresos. Asimismo, lo hará de las

24 BRUÑ̃́N BARBERÁ, F.M., ibídem, pág. 173. 
actividades o cargos que desempeñe a efectos del examen de incompatibilidades, debiendo comunicar las alteraciones que se produzcan a lo largo del mandato. La referida declaración quedará custodiada en la Secretaría General de la Cámara a disposición de la Comisión de Estatuto de los Diputados". De igual modo, en el art. 7.5 de la Ley 16/2001, de 20 de diciembre, del Defensor del Pueblo de Castilla-La Mancha, se prevé que el Defensor y los Adjuntos o Adjuntas y los asesores y asesoras de la Institución están obligados a presentar declaración sobre actividades, bienes y rendimientos. Y así también se contempla en el art. 11.5 de Ley 6/2006, de 2 de mayo, del Defensor del Pueblo Riojano y en el art. 12 de la Ley 6/2008, de 20 de noviembre, del Defensor del Pueblo de la Región de Murcia.

En todo caso, nada obsta a que el Defensor del Pueblo y sus Adjuntos puedan realizar voluntariamente declaraciones de actividades y bienes - de hecho, así ha ocurrido- presentándose ante la Junta de Coordinación y Régimen Interior y pasando a posterior custodia por el Secretario General del Defensor del Pueblo.

\section{Concurrencia de la Situación de incompatibilidad}

Los supuestos de referencia funcionan como causas de incompatibilidad y no de inelegibilidad, ya que la concurrencia de alguna de ellas no va a constituir impedimento para que el candidato llegue a ser elegido, siempre y cuando renuncie a la causa de incompatibilidad antes de tomar posesión de su cargo. Según el apdo. $2^{\circ}$ del art. $7^{\circ}$ de la LODP éste deberá cesar, dentro de los diez días siguientes a su nombramiento y antes de tomar posesión, en toda situación de incompatibilidad que pudiera afectarle, entendiéndose en caso contrario que no acepta el nombramiento. Y según el apdo. $3^{\circ}$ de este mismo artículo, si la incompatibilidad fuese sobrevenida una vez posesionado del cargo, se entenderá que renuncia al mismo en la fecha en que aquélla se hubiese producido.

A priori no tendría que resultar conflictiva la aplicación de estos preceptos, pues del prestigio y talla moral de la persona que vaya a ser nombrada como Defensor cabe esperar toda su colaboración para cesar en cualquier situación de incompatibilidad que le afecte. Pero, al menos teóricamente, cabría la posibilidad de que se plantease algún supuesto dudoso, fronterizo, no previéndose nada al respecto, como así ocurre respecto a muchos Comisionados Autonómicos.

Así, en el art. 7.4 de la Ley 11/1988, de 26 de diciembre, del Síndic de Greuges de la Comunidad Valenciana se establece que: "La Comisión de Peticiones de las Cortes Valencianas será la competente para dictaminar cualquier situación de duda o conflicto sobre las circunstancias de incompatibilidad que pudieran afectar al Síndico de Agravios". Semejante previsión se contiene en el artículo 7.5 de la Ley Foral 4/2000, de 3 de julio, del Defensor del Pueblo de la Comunidad Foral de Navarra, siendo la Comisión de Régi- 
men Foral del Parlamento de Navarra la competente para dictaminar por mayoría de tres quintas partes de los votos cualquier estado de duda o controversia sobre las situaciones de incompatibilidad que pudieran afectar al Defensor, elevándose su dictamen al Pleno del Parlamento. Y en el art. 7.4 de la Ley 9/1983, de 1 de diciembre, del Defensor del Pueblo Andaluz, a favor de la Comisión de Gobierno Interior y Peticiones; en el art. 8.2 de la Ley 7/2001, de 31 de julio, del Diputado del Común, respecto a la Comisión del Estatuto de los Diputados; en el art. 7.4 de la Ley 16/2001, de 20 de diciembre, del Defensor del Pueblo de Castilla-La Mancha, respecto a la Comisión de Asuntos Generales; y en el art. 11.4 de la Ley 6/2006, de 2 de mayo, del Defensor del Pueblo Riojano, respecto a la Comisión de Peticiones y Defensa del Ciudadano.

A nuestro juicio, sería conveniente una reforma legal de forma que, por ejemplo, la Comisión Mixta Congreso-Senado encargada de relacionarse con el Defensor del Pueblo, fuese la que dictaminase sobre la concurrencia de una situación de incompatibilidad en el Defensor del Pueblo y lo eleve a los Plenos de las Cámaras. Al fin y al cabo corresponde a dicha Comisión informar a los Plenos en cuantas ocasiones sea necesario (art. 2.2 LODP), proponer a los Plenos de las Cámaras el candidato o candidatos Defensor (art. 2.3), así como dar previa conformidad al nombramiento de los Adjuntos (art. 2.6). O bien que lo fuese la Comisión del Estatuto de los Diputados del Congreso, siguiendo el ejemplo canario ${ }^{25}$.

En cuanto a lo establecido en el artículo 7.3 LODP para los casos de incompatibilidad sobrevenida, podría igualmente plantearse el caso de situaciones dudosas, para los cuales vale lo dicho anteriormente. Si no existe duda alguna, por ejemplo si el Defensor se afilia a un partido político, puede entenderse que efectivamente renuncia al cargo desde la fecha en que se produzca la afiliación. Pero si el supuesto es dudoso la solución planteada no parece la más acertada, de forma que sería más razonable que dictaminada y declarada la situación de incompatibilidad se le concediera el plazo señalado en el apdo. $2 .^{\circ}$ de este artículo para cesar en la situación de incompatibilidad, y si no lo hiciera, entender entonces que renuncia al nombramiento ${ }^{26}$. Así se ha previsto respecto a algunos Comisionados Autonómicos, como el Síndic de Greuges de Cataluña y el de las Islas Baleares.

\section{INCOMPATIBILIDADES POSTERIORES AL EJERCICIO DEL CARGO}

Parte de la doctrina se ha mostrado inquietada por la ausencia en la LODP de un sistema de incompatibilidades posterior al ejercicio de su mandato. Se trataría con ello de evitar el aprovechamiento ilegítimo, con posterioridad al cese, de contactos e informaciones obtenidas durante el tiempo de

25 En este sentido se pronuncia BRUÑén BARBERÁ, F.M., ibídem, pág. 178.

26 BRUÑÉN BARBERÂ, F.M., ibídem, pág. 178. 
desempeño del cargo público y/o evitar el desempeño ilícito —o inmoral— del mismo basado en la previsión de obtención de futuros réditos, provechos, o beneficios.

Este sistema sí se contempla, por ejemplo, en el artículo 8 de la Ley 5/2006, de 10 de abril, de conflictos de intereses de los miembros del Gobierno y Altos Cargos de la Administración, donde se establecen una serie de limitaciones al ejercicio de actividades privadas con posterioridad al cese: "1.Durante los dos años siguientes a la fecha de su cese los altos cargos, a los que se refiere el artículo 3, no podrán desempeñar sus servicios en empresas o sociedades privadas relacionadas directamente con las competencias del cargo desempeñado. A estos efectos se considera que existe relación directa cuando se den cualquiera de los siguientes supuestos de hecho: a) Que los altos cargos, sus superiores a propuesta de ellos o los titulares de sus órganos dependientes, por delegación o sustitución, hubieran dictado resoluciones en relación con dichas empresas o sociedades. b) Que hubieran intervenido en sesiones de órganos colegiados en las que se hubiera adoptado algún acuerdo o resolución en relación con dichas entidades. 2. Los altos cargos, regulados por esta Ley, que con anterioridad a ocupar dichos puestos públicos hubieran ejercido su actividad profesional en empresas privadas, a las cuales quisieran reincorporarse, no incurrirán en la incompatibilidad prevista en el apartado anterior cuando la actividad que vayan a desempeñar en ellas lo sea en puestos de trabajo que no estén directamente relacionados con las competencias del cargo público ocupado ni puedan adoptar decisiones que afecten a éste. 3. Durante el período de dos años a que se refiere el primer apartado de este artículo no podrán celebrar por sí mismos o a través de sociedades o empresas participadas por ellos directa o indirectamente en más del 10 por 100 contratos de asistencia técnica, de servicios o similares con las Administraciones Públicas, directamente o mediante empresas contratistas o subcontratistas. 4. Las personas que hubiesen desempeñado alguno de los altos cargos comprendidos en el artículo 3 deberán efectuar, durante el período de dos años a que se refiere el primer apartado de este artículo, ante la Oficina de Conflictos de Intereses prevista en el artículo 15, declaración sobre las actividades que vayan a realizar, con carácter previo a su inicio. En el plazo de un mes la Oficina de Conflictos de Intereses se pronunciará sobre la compatibilidad de la actividad a realizar y se lo comunicará al interesado y a la empresa o sociedad en la que fuera a prestar sus servicios. 5. Cuando la Oficina de Conflictos de Intereses estime que la actividad privada que quiera desempeñar una persona que hubiera ocupado un alto cargo vulnera lo previsto en el apartado 1, se lo comunicará al interesado y a la empresa o sociedad a la que fuera a prestar sus servicios, que formularán las alegaciones que tengan por convenientes. Analizadas las alegaciones, la Oficina propondrá la resolución que proceda. 6 . Durante los dos años posteriores a la fecha de cese, aquéllos que ingresen a la función pública y presten servicios retribuidos mediante honorarios, arancel o cualquier otra forma de contraprestación económica a personas físicas o jurídicas de carácter privado se inhibirán en todas 
aquellas actuaciones privadas que guarden relación con las competencias del alto cargo ejercido".

A la hora de proponer un régimen de incompatibilidades en este sentido, hay que tener presente que el Defensor no ejerce una función de supervisión de las actividades privadas, salvo los servicios prestados por particulares en virtud de un acto administrativo habilitante (art. 28.2 LODP). Pero también que las entidades privadas y los empresarios individuales pueden ser sujetos activos de una queja contra una actuación administrativa, y que una resolución favorable de ésta podría suponer un beneficio para la entidad o sujeto reclamante. Con lo que si el Defensor entrase al servicio del sujeto reclamante con posterioridad a la finalización del mandato podría quedar en entredicho su imagen pública.

Bruñén Barberá, por ejemplo, encuentra acertado el establecimiento de un sistema de "vacatio" indemnizado que durante un período de dos años que es el que normalmente se contempla para incompatibilidades posteriores al ejercicio de un cargo- suponga la prohibición al Defensor de realización de actividades públicas o privadas, con la posibilidad de exceptuar o compatibilizar alguna actividad poco —o nada- comprometedora, como la académica o de investigación ${ }^{27}$. Por su parte, el artículo 8.5 de la Ley $7 / 2001$, de 31 de julio, del Diputado del Común establece que: "quienes hubiesen desempeñado el cargo del Diputado del Común no podrán, durante el año siguiente a la fecha del cese, intervenir por sí o mediante apoderamiento, en la tramitación, ejecución o impugnación de expedientes concretos sobre los que haya intervenido". Solución ésta última que nos parece bastante proporcionada incluso ampliada a un año más.

\section{EPÍlOGO}

De todo lo expuesto con anterioridad, resaltaríamos especialmente que, en orden a mejorar el status de independencia e imparcialidad del Defensor del Pueblo sería conveniente una reforma legal que, en materia de incompatibilidades, especificase qué actividades no deben ser consideradas de mera administración del patrimonio personal o familiar, al poder implicar un detrimento de las funciones propias del cargo o comprometer su imparcialidad e independencia. También resultaría recomendable la obligatoriedad de efectuar declaración de actividades y bienes patrimoniales por su demostrada eficacia en frenar el tráfico de influencias. Y la previsión de un sistema de incompatibilidades posterior al ejercicio del mandato, para evitar el desempeño ilícito o inmoral del mismo en atención a la previsión de la obtención de futuros beneficios, o el aprovechamiento ilegítimo, con posterioridad al cese, de contactos e informaciones obtenidas durante el tiempo de desempeño del cargo.

27 BRUÑÉN BARBERÁ, F.M., ibídem, pág. 175. 
TITLE: Ombudsman's prerogatives and incompatibilities: some reform proposals.

ABSTRACT: In order to contribute to improve the status of independence and impartiality of Ombudsman-Institution, we offer a detailed analysis about the specialties of Ombudsman's prerogatives and the proposal of some legislative reforms about incompatibilities: restrictions to the administration of personal patrimony, legal duty of declaration of activities and patrimony, and the prevision of certain incompatibilities subsequent to cessation.

Resumen: Con el objetivo último de poder contribuir a mejorar el status de independencia e imparcialidad de la institución del Defensor del Pueblo, ofrecemos un minucioso análisis de las especialidades que presentan las prerrogativas del Defensor del Pueblo frente a las parlamentarias, y la propuesta de determinadas reformas legislativas en materia de incompatibilidades: posibles limitaciones en la administración del patrimonio personal, obligación de declaración de actividades $y$ bienes patrimoniales y previsión de ciertas incompatibilidades posteriores al ejercicio del cargo.

KeY WoRDS: Ombudsman. Prerogatives. Incompatibilities.

Palabras Clave: Defensor del Pueblo. Prerrogativas. Incompatibilidades.

FECHA DE RECEPCIÓN: 20.05.2010. FECHA DE ACEPTACIÓN: 28.07.2010. 